\title{
iV2G Charging Platform
}

\author{
Vítor Monteiro, João C. Ferreira, Gabriel Pinto, Delfim Pedrosa and João L. Afonso
}

\begin{abstract}
This paper describes an intelligent Vehicle to Grid (iV2G) Charging Platform for plug-in hybrid and electric vehicles that can be used at user's home, and which includes a mobile control system. The car drivers can control remotely the charging or discharging process through a mobile communication device. This mobile communication device can also gather information about charging places, their availability and the best road paths to reach them, as well as energy market prices, informing the best periods to charge the car regarding the energy costs.
\end{abstract}

\section{INTRODUCTION}

$\mathrm{T}$ he upcoming reality of smart grids, Electric Vehicles (EVs), and electrical power markets raise a diversity of problems, because an end-user is no longer a passive client. Also the charging and discharging process of an EV needs assistance of an intelligent process in order to find cheaper prices to identify available charging slots (in public areas) and to provide other useful information to the EVs owners.

This upcoming reality will require several developments and studies regarding the interaction of smart grid, users, markets and others. EVs and PHEVs (Plug-In Hybrid Electric Vehicles) are seen as one of the most promising means to improve the near-term sustainability of the transportation and stationary energy sectors [1]. Researchers have developed analyses and demonstrations of electric vehicles charging behaviour, but the long-term infrastructure and information architectures required for a massive market infiltration of EVs and PHEVs are less defined. These studies have shown that the electrical grid could assimilate a significant fraction of a hypothetical national fleet of plug-in vehicles performing $\mathrm{V} 2 \mathrm{G}$ (Vehicle to Grid) charging without significant infrastructure improvement and without centralized charging control [2, 3, 4, 5]. Central utility control of EVs and PHEVs performing V2G has been shown to have significant benefits for the grid system operator by enabling dynamic demand response, load profile flattening, and improved generation resource utilization [6, $7,8]$. However, fewer studies have considered the impacts of a fleet of EVs and PHEVs in the V2G system. Demonstrations have shown that single vehicles can

Manuscript received on July 15, 2010. This work was supported in part by the FCT (Fundação para a Ciência e a Tecnologia) and the MITPortugal Program, funding Project MIT-Pt/EDAM-SMS/0030/2008.

Vítor Monteiro, Delfim Pedrosa, Gabriel Pinto and João L. Afonso are with the University of Minho, Department of Industrial Electronic, Largo do Paço, 4704-553 Braga, Portugal. (e-mails: vmonteiro@dei.uminho.pt, dpedrosa@dei.uminho.pt, gpinto@dei.uminho.pt, jla@dei.uminho.pt).

João C. Ferreira is with the GuIAA-ISEL, Lisbon, Portugal. Rua Conselheiro Emídio Navarro 1, 1900-049 Lisbon, Portugal. (e-mail: jferreira@deetc.isel.ipl.pt). interface to the grid for $\mathrm{V} 2 \mathrm{G}$ applications and that given sufficient information infrastructure, the grid operator could control power flow from and to the vehicle $[9,10]$.

So, the intention of the work presented in this paper is to provide an open charging platform for scientific community use, in order to contribute for the development of the V2G technologies. Therefore, in this paper it will be described the intelligent Vehicle to Grid (iV2G) Charging Platform creation, with the hardware and software description. Special emphasis will be given to the creation of the communication mobile device application that will be an important user add on, facilitating the interactive process between the users, the charging process and the energy market.

To handle this topic an investigation effort of two main universities in Portugal is being done, with contribution of two distinct areas: Computer Science and Electrical Power Systems (including Power Electronics).

\section{Electric Vehicle AND Charging System APPROACHES}

On Fig. 1 are identified the main vehicle types relatively to the energy power supply. The main classes are:

1 - The Internal Combustion Engines (ICE), which produce high $\mathrm{CO} 2$ emission.

2 - The Hybrid Electric Vehicles (HEV), which combine an ICE with an electric motor, and that were first commenced in 1997, in Japan, with the introduction of Toyota Prius. The main characteristic of this type of vehicle is the operation of the ICE on its most efficient interval, with the help of the electric motor.

3 - The PHEV which are hybrid electric vehicles with additional capability to be charged from the electrical grid.

4 - The EV or Electric Drive Vehicles (EDV), which employ only electric motors to drive the vehicles, and that use batteries to store energy.

5 - The Fuel Cell Electric Vehicles (FCEV), which are similar to the EV, but that use fuel cells to produce electrical energy from hydrogen.

There are five main methods of charging EV batteries (see Fig.2): (1) constant voltage; (2) constant current; (3) taper current (where the charging is performed from a crude unregulated constant voltage source, and the current diminishes as the cell voltage builds up); (4) pulsed charge (where pulsed chargers feed the charge current to the battery in pulses - the charging rate, based on the average current, 
can be precisely controlled by varying the width of the pulses, typically of about one second); (5) a combination of the previous of charging the batteries. As shown this Fig.2 each type of electrochemical batteries has their specific method to charging.

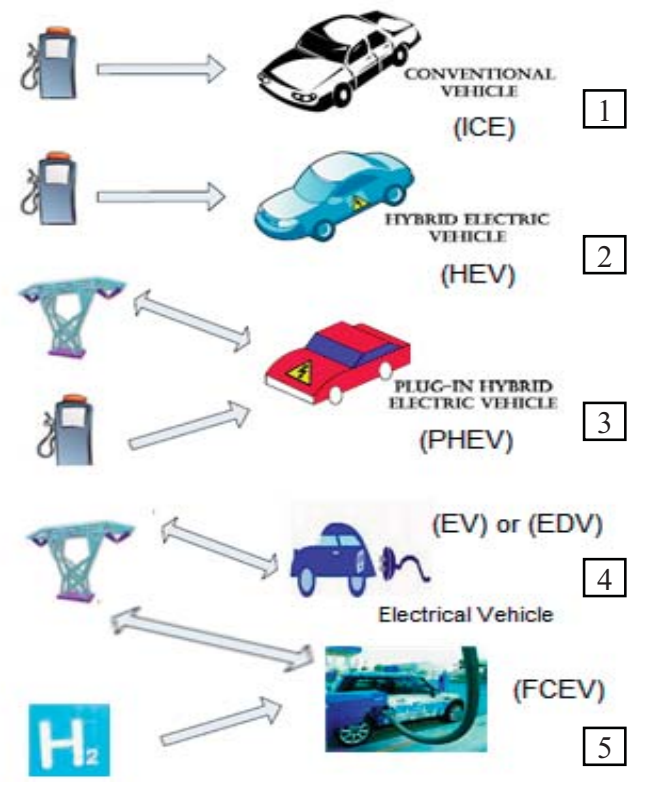

Fig.1. Main vehicle types

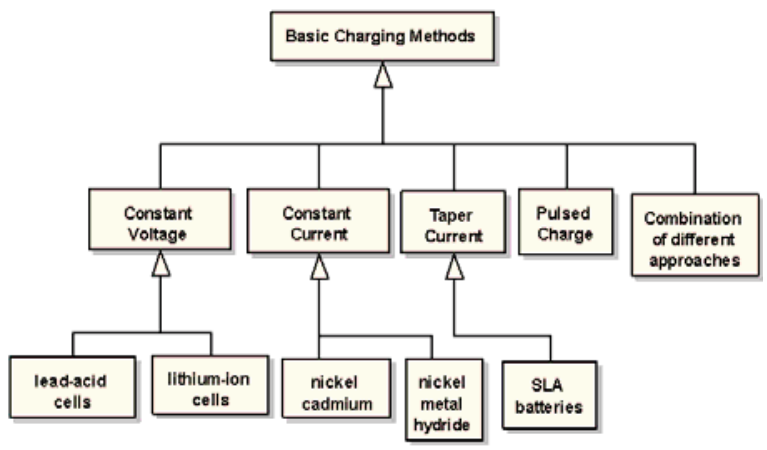

Fig.2. Main methods of charging EV batteries

The recent increase in EVs using batteries represent a gain for independence relatively to the unstable cost of the oil in the international markets, and contributes to reducing the emission of greenhouse gases, like CO2. However, with this increasing use of batteries, it is intended that the methods for charging and discharging batteries are beneficial, not only to the lifespan of the batteries, but also to preserve the power quality of the electrical grid. In this sense, it is very important to provide EVs with "intelligent" equipment for charging and discharging the batteries (the iV2G Charging Platform). This called "intelligent" equipment shall guarantee that the batteries are charged with the best possible algorithms, according to the information given by the batteries manufacturers, in order to extend as much as possible the lifespan of the batteries (during slow charging process), or to speed up the charging time, without compromising the batteries lifespan (during fast charging process). At the same time, this equipment must ensure that batteries are charged from the electrical grid with an almost sinusoidal current consumption (to minimize the Total Harmonic Distortion of the current), and with unitary power factor, ensuring the power quality of the energy in electrical grid.

During the discharge of the batteries, when the stored energy in batteries is delivered to the electrical power grid (with the intention of guarantee the stability of the electrical grid), the iV2G Charging Platform shall guarantee that energy from batteries is supplied with a sinusoidal waveform of electrical current. This equipment must also assure that only a previously agreed (by the electric vehicle owner) amount of energy will be delivered back to the electrical grid (e.g., if a long trip is planned to occur soon, the equipment will not allow the discharging of the batteries).

In typical EVs, when it is necessary to charge the batteries, the energy comes from the electrical grid to the batteries in unidirectional mode, without any control in electrical grid. However, with the iV2G Charging Platform proposed in this paper (see Fig.3), the batteries can be charged or discharged, from the moment that the vehicle is connected to the electrical grid, according to a compromise assumed between the EV owner and the electrical grid company.

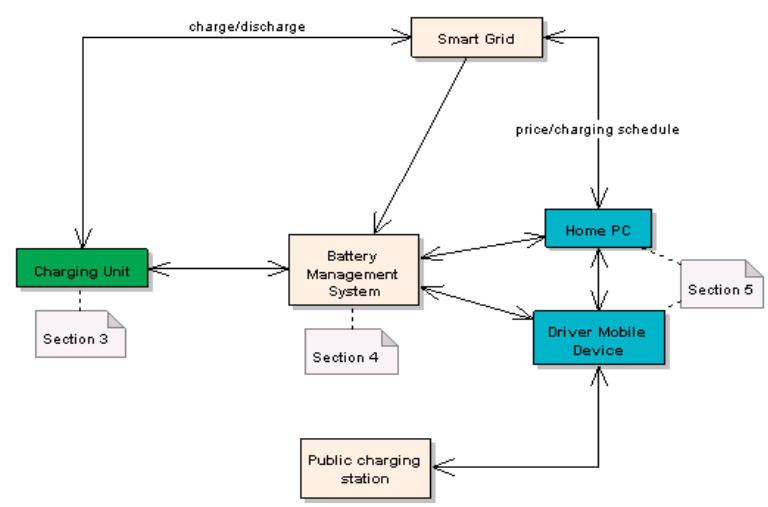

Fig.3. iV2G system main modules

\section{CHARGING DEVICE}

Fig.4 shows the proposed diagram of the iV2G Charging Platform that is being implemented to be used with EVs and PHEVs [11]. This equipment, with the proper control allows charging the batteries with different algorithms (constant voltage, constant current, constant current followed by constant voltage, or other), and also permits deliver the energy from the batteries back to the electrical grid.

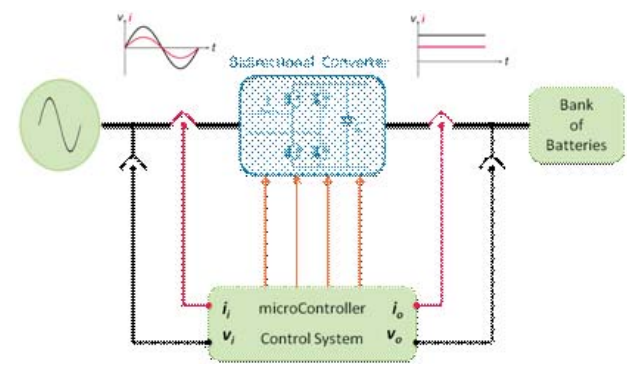

Fig.4. Conceptual diagram of the developed equipment 
The power converter of the iV2G Charging Platform is presented in Fig.5. It consists in a bidirectional converter that uses four power semiconductors (IGBTs FGA25N120ANTD $25 \mathrm{~A}-1200 \mathrm{~V})$, two snubber capacitors $(1 \mathrm{uF}-400 \mathrm{~V})$, an inductance $(5 \mathrm{mH}-10 \mathrm{~A})$ to interface with the electrical grid side (AC side), and a capacitor $(4.7 \mathrm{mF}-450 \mathrm{~V})$ in the batteries side (DC side). To make the pre-charge of the capacitor are used two resistors (100 $\Omega$ - $50 \mathrm{~W}$ ) connected in parallel, along with their command circuit. The batteries bank, not presented in this Fig., is constituted by four lead-acid batteries (each one with $12 \mathrm{~V}$ and $44 \mathrm{Ah}$ ) connected in series.

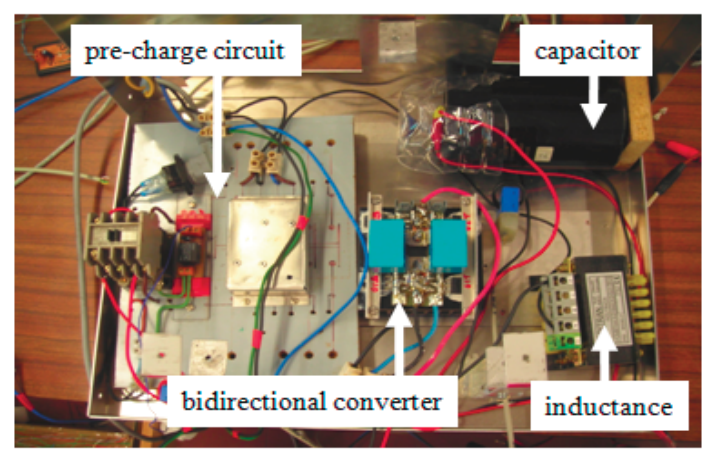

Fig.5. Developed power converter

The developed control system is presented in Fig.6, and is composed by a Microcontroller (PIC32MX360F512L), a Digital Analog Converter (DAC - DAC712P), Voltage and Current Sensors (LEM - Hall Effect Sensors), a Signal Conditioning Circuit, a Circuit to Detect Errors, a Command Circuit to the IGBTs, and a Drivers Circuit to establish the interface between the Command Circuit and the IGBTs. The Microcontroller receives the signals of voltages and the currents from the Signal Conditioning Circuit and implements an algorithm to charge or discharge the batteries.

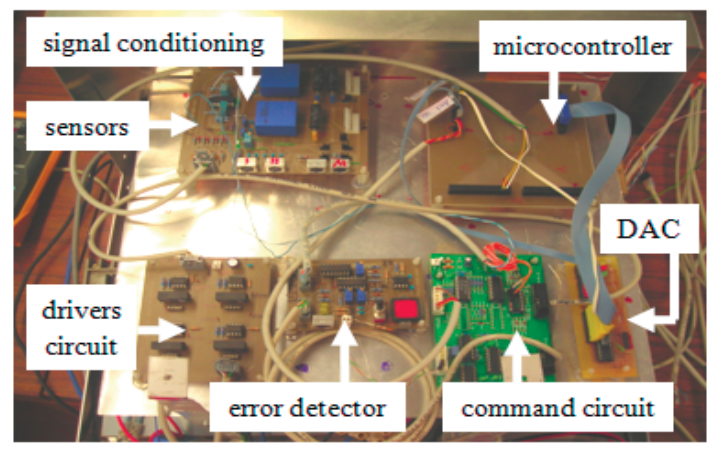

Fig.6. Developed Control System

\section{BATTERY MANAGEMENT SYSTEMS - BMS}

Independently of the batteries technology, and of their nominal values, there are three main objectives common to all Battery Management Systems (BMS): (1) To protect the batteries against damages, as over voltages, under voltages, over currents or over temperatures; (2) To prolong the lifespan of the batteries; (3) To maintain the batteries in a state in which they can fulfill the functional requirements of the application for which they were specified. To achieve these objectives the BMS may incorporate one or more of the functions presented in Fig.7. The quality of the BMS increases with the number of the functions that it can play.

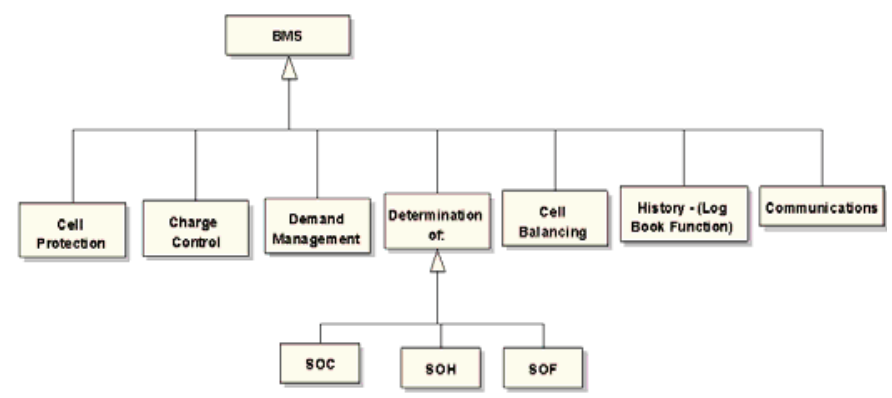

Fig.7. Main functions of a BMS system

State of Charge (SOC) [12] is a percentage commonly used for describing the available energy in battery as a percentage of the full battery capacity. It helps to gage the level of energy in the battery. The most frequent used equation for defining and calculating the state of charge of a battery is: $\mathrm{SOC}=$ (remaining battery capacity) $/$ (nominal battery capacity) (1)

This nominal capacity of the battery is measured with a very small discharging current (such as $\mathrm{C} / 30$ or less), with the battery being discharged at room temperature.

State of Health (SOH) [12] indicates aging or abnormal behaviours of the battery. In a battery being charged and discharged along its lifespan, the amount of energy that the battery can hold tends to decrease in comparison with a new battery. If a battery was used in extreme conditions, such as in a very high operating temperature, or with excessive charging/discharging current, the $\mathrm{SOH}$ of the battery would deteriorate, causing the battery to hold less energy even if it was fully charged. Literature suggests that the $\mathrm{SOH}$ of a battery can only be estimated but not measured. However there are battery tests or signals that would indicate the $\mathrm{SOH}$ of a battery. One could use a full discharge test to measure the capacity in a fully charged battery and use the measured capacity to compare with the battery rated capacity. In this case:

$\mathrm{SOH}=($ measured battery capacity) $/$ (rated battery capacity) (2)

Since a battery holds less power as it ages, the measured capacity from the full discharge test decreases. As a result the SOH of a battery can be calculated as percentage, just like the SOC. The Energy Institute of Battery Research Group suggests that a battery is at its end of lifespan when the calculated $\mathrm{SOH}$ approaches $80 \%$. Other physical characteristics of a battery can also be used to estimate its $\mathrm{SOH}$. The experimental results prove that in a battery, due to its aging (characterized by its $\mathrm{SOH}$ ), internal resistance increases, and consequently increase the loss of active power and the self-discharge of the battery.

State of Function (SOF) [12] is the capability of the battery to perform a specific task which is relevant for the functionality of a system powered by the battery. Batteries with different SOC or SOH perform very different under the 
same operating conditions. Different operating environment to the same batteries, such as different operating temperatures, also produce very different performance, and provide different amount of energy. The SOF of a battery can be viewed as a function of the battery's SOC, SOH and operating temperature.

\section{Web BASED Mobile APpliCATION}

To facilitate user interaction with charge/discharge process, a remote web application (to run in a mobile device or desktop) is integrated, because, due to the future energy market, it is necessary to operate a change on users needs to interact fast with the battery charge/discharge system. These features are to integrate on our project, where energy distribution limitations will be considered in a smarter charge/discharge process, and where limitation of local low voltage distribution is also taken into account. BMS and charge/discharge device have the capacity to communicate with the user's home computer or mobile device using cell phone, Wi-Fi, Wimax or ZigBee. The system main requisites are identified in Fig.8: (1) log process to manage charge/discharge, where the BMS should receive relatively simple commands such as charge the battery, wait for further instructions, return energy to the electrical grid, and archive transactions for further analyses; (2) driver mobile device GPS will track the user's movements in an offline mode (avoid user charges of GPRS connection), (3) guidance for charging stations, their location, and spot to charging; (4) the user will establish a profile (stored on user's PC) where we defines their habits (as number and time of travels per week) travel time and distance, weekend habits) and also the minimum SOC level (that allows to drive a minimum distance); (5) energy market functions, such as price to sell and buy and the creation of driver communities to create enough power for electrical vehicle to be an energy market player (not covered in this paper); and (6) a tracking application is installed on a mobile device and configured to work in offline mode (to avoid charging expenses for user). The application analyzes all logs files of the charge and discharge process, receives orders to sell or buy energy, changes the SOC level, and the time to use EVs and PHEVs, among others options.

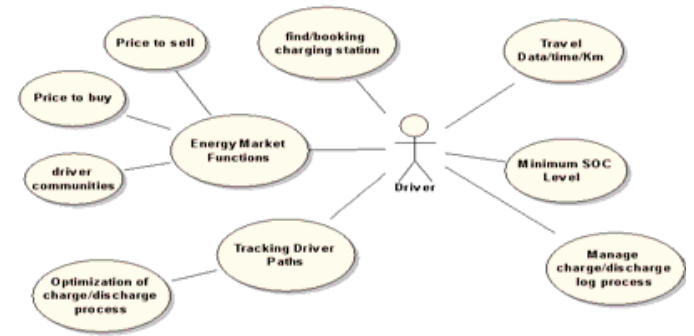

Fig.8. Use case for the description of main requisites of the Web Based Mobile Application

Details for this implementation can be found at [13]. We have a central server application, were we store all related data in a SQL database. Access to this application is performed from mobile devices and desktop devices through a web interface. A visualization browser was developed in a master project [14] for windows mobile PDA. Map visualizations and guiding directions are performed through Google Maps using Web Services. In a future version we are trying to integrate real time traffic information and public information.

\section{Case Study - Mobi_Guimarães Project}

Mobi_Guimarães is a project for Guimarães (Portuguese city), that will be European Capital of Culture in 2012. This is a QREN (Quadro de Referência Estratégio Nacional) project approved under POVT (Programa Operacional Valorização do Território). In this Project an EV will be available with three charging spots. This is a lab project in a real environment for testing, that includes, the ITS platform, energy management systems, mobility polices, charging devices, among others. In this environment test, first were simulated, with different approaches, the charge and discharge of the batteries. The first results obtained with simulations and the experimental results are presents in this paper. The complete described tool will be tested in a real environment in 2012.

The tests were performed in two main directions: (1) analyze the batteries and the electrical grid performances through simulations (using the software PSCAD - Power System Computer Assisted Design) and experimental results [11]; and (2) battery SOC level analysis in a day time and days against days.

To iV2G Charging Platform, the simulations were made during the charging and the discharging of a lead-acid batteries bank (48 V - $44 \mathrm{Ah})$. In the first simulation was made the charge with the method constant voltage, which consist in apply constant voltage to the batteries while the current decreases until the end of the charge. In Fig.9 and in Fig. 10 are shown the simulation results obtained. As shows Fig.9 the current in electrical grid side is sinusoidal with unitary power factor, and as show the Fig.10 the voltage applied to the batteries remains constant. On other hand, in the second simulation was made the discharging with a method that consists in provide sinusoidal current to the electrical grid always with the same amplitude. In Fig. 11 are shows the simulation results obtained. Once more, the current in the electrical grid side is sinusoidal with unitary power factor, but the current is in opposite phase with the voltage. In both cases, the high frequency that appears in the electrical grid current is due to the used switching technique.

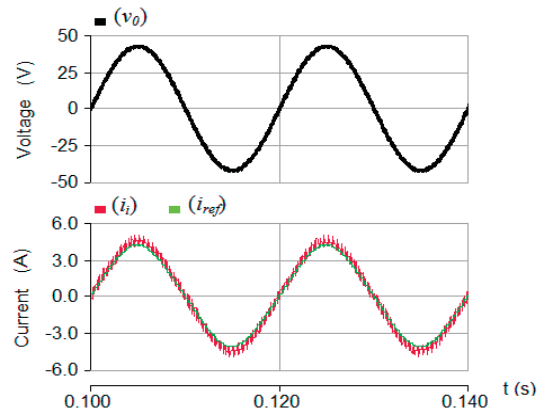

Fig.9. Simulations results: Voltage $\left(v_{i}\right)$, current $\left(i_{i}\right)$, and reference current $\left(i_{\text {ref }}\right.$ in the electrical grid side during the charging of the batteries 


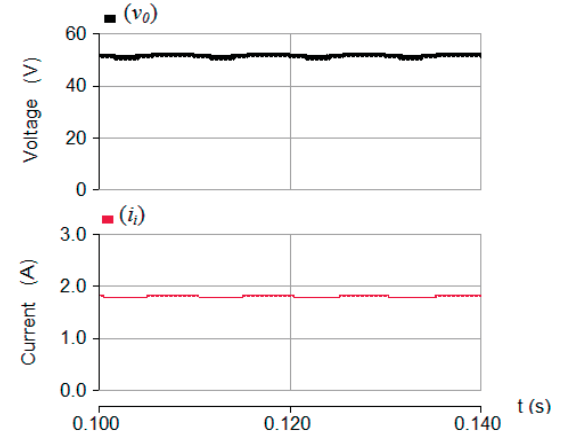

Fig.10. Simulations results: Voltage $\left(\mathrm{v}_{\mathrm{o}}\right)$, and current $\left(\mathrm{i}_{\mathrm{o}}\right)$, in the batteries side during the charging of the batteries

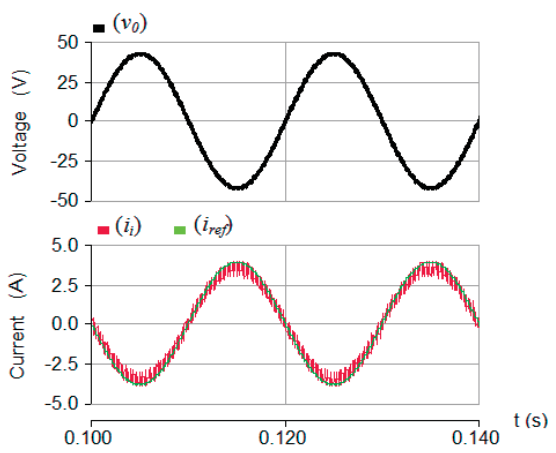

Fig.11. Simulations results: voltage $\left(\mathrm{v}_{\mathrm{i}}\right)$, current $\left(\mathrm{i}_{\mathrm{i}}\right)$, and reference current ( $\left.i_{\text {ref }}\right)$ in the electrical grid side during the discharging of the batteries

The experimental results were obtained with a lead-acid batteries bank ( $48 \mathrm{~V}-44 \mathrm{Ah})$, during their charge and discharge. To the batteries bank charge was used the method constant voltage. As show the Fig.12, during the charging, the consumption current is sinusoidal with unitary power factor and the voltage applied for charge the batteries is constant. For this method, the end of the charge is determined by the current in the batteries, and occurs when this current is near to zero.

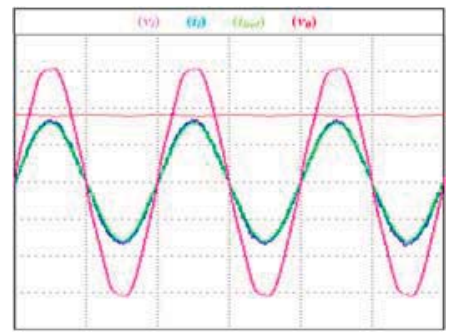

Fig.12. Experimental results: voltage $\left(\mathrm{v}_{\mathrm{i}}\right)$, current $\left(\mathrm{i}_{\mathrm{i}}\right)$, and reference current $\left(i_{\text {ref }}\right)$ in the electrical grid side, and voltage $\left(\mathrm{v}_{0}\right)$ in the batteries side, during the charging of the batteries

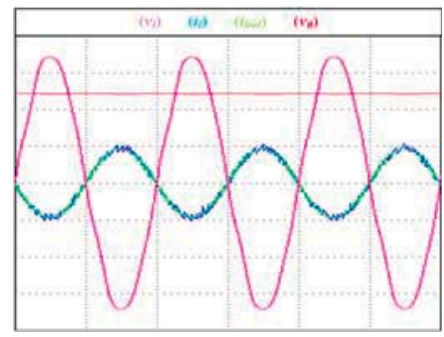

Fig.13. Experimental results: voltage $\left(\mathrm{v}_{\mathrm{i}}\right)$, current $\left(\mathrm{i}_{\mathrm{i}}\right)$, and reference current $\left(\mathrm{i}_{\text {ref }}\right)$ in the electrical grid side, and voltage $\left(\mathrm{v}_{0}\right)$ in the batteries side, during the discharging of the batteries
The discharging of the batteries consist in provides sinusoidal current with unitary power factor to the electrical grid always with the same amplitude. In this method, to the complete discharging, the end of the discharge is determined by the minimal voltage in the batteries, or when the process is interrupted. The results obtained are presented in Fig.13.

From the log files of the charge or discharge process, it is possible check the SOC levels of the different batteries systems and with they study the behavior of users, such as: driving times, traveled distances, and market behavior. Mining this information it is possible generate an added value, like the evolution of the active power during the charging of the batteries for different days, based on different driver's profiles (e.g. different daily distances traveled, times required to charging, $\mathrm{V} 2 \mathrm{G}$ control, and the possibility of charging during working times or not). Fig.14, illustrates this aspects with a charging scenario for an EV with a $10 \mathrm{~kW}$ batteries, when is parked in work. Store and analyze the data of the charge and discharge is an added value, because with them it is possible the process optimization, taking into account, the users habits and get together useful information for energy producers.

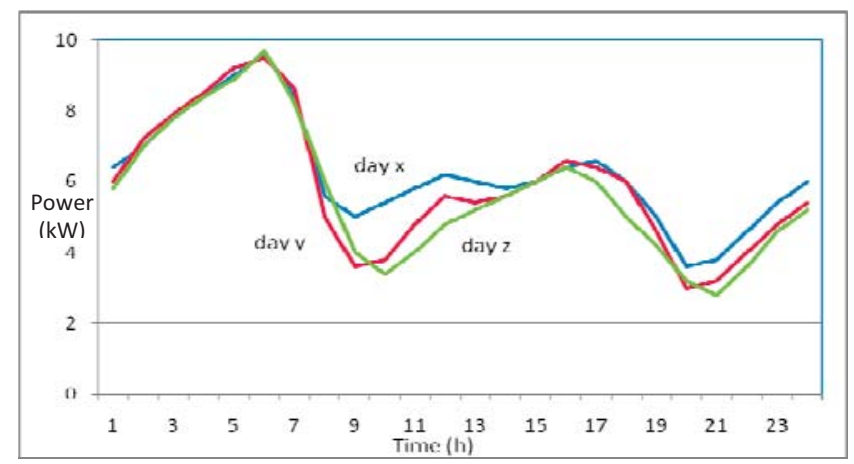

Fig.14. Batery charging function of day time for different days for an EV of $10 \mathrm{~kW}$

Mobi_Guimaraes will have three charging stations. Using Google Maps we give directions, we present a booking interface and we show the users the charging slots available. Electricity prices are simulated with a random function, where we define maximum and minimum values and users define prices that they are interested on buying and sell electricity and a minimum SOC level is defined to perform this function.

\section{CONCLUSION}

With the intelligent Vehicle to Grid (iV2G) Charging Platform proposed in this paper, the main goal is to create a platform to assist the process of the charge and discharge of batteries banks used in EVs (Electric Vehicles) and PHEVs (Plug-In Hybrid Electric Vehicles). Different approaches can be tested and driver's behavior can be studied from the stored information, during the charge and discharge of the batteries banks.

The main goals of this researching work are: to contribute to the power quality of the electrical grid; and to develop 
tools, to bring and to send information related with the electric cars use and to the electrical power grid (application to run in a mobile device). These applications will bring added value to the vehicle drivers and can be used taking into account the energy market (electrical energy prices), the control of the charging process (due to electrical infrastructure limitations), and a better management of the charging and discharging process.

As demonstrated in the obtained results, it is possible to control the charge and the discharge of the batteries bank, with clear benefits to the batteries, mainly to their lifespan, and at the same time, to preserve the power quality of the electrical grid, since during the charge, the current consumption is kept sinusoidal with unit power factor, and during the discharge, the current injected is also maintained sinusoidal. These characteristics are good contributions to the V2G concept, and can be implemented in equipments that can be put inside or outside the EVs and PHEVs.

In a test project (Mobi_Guimarães Project) it will be possible to obtain data in a more real scenario regarding the benefits of an iV2G Charging Platform, like the one described in this paper.

\section{ACKNOWLEDGEMENT}

The authors are grateful to the FCT (Fundação para a Ciência e a Tecnologia) and to the MIT-Portugal Program, for funding the Project MIT-Pt/EDAM-SMS/0030/2008.

\section{REFERENCES}

[1] T.H. Bradley, A.A. Frank, Renewable and Sustainable Energy Reviews 13 (2009) 115-128.

[2] Environmental Assessment of Plug-in Hybrid Electric Vehicles. Volume 1:Nationwide Greenhouse Gas Emissions, EPRI, Palo Alto, CA 1015325, 2007.

[3] M.C. Kintner-Meyer, et al., Impacts Assessment of Plug-in Hybrid Vehicles on Electric Utilities and Regional US Power Grids: Part 1: Technical Analysis, Pacific Northwest National Laboratory (PNNL), 2007 (PNNL-SA-61669).

[4] M. Duvall, How many plug-in hybrids can a smart grid handle? in: Plug-in 2008 Conference and Exposition, San Jose, CA, 2008.

[5] S.W. Hadley, A.A. Tsvetkova, Potential Impacts of Plug-in Hybrid Electric Vehicles on Regional Power Generation, Oak Ridge National Laboratory (ORNL), 2007 (ORNL/TM-2007/150).

[6] W. Short, P. Denholm, Preliminary Assessment of Plug-in Hybrid Electric Vehicles on Wind Energy Markets, National Renewable Energy Lab (NREL), 2006 (NREL/TP-620-39729).

[7] P. Denholm,W. Short, Evaluation of Utility System Impacts and Benefits of Optimally Dispatched Plug-in Hybrid Electric Vehicles, National Renewable Energy Laboratory (NREL), 2006 (NREL/TP620-40293).

[8] K. Parks, et al., Costs and Emissions Associated with Plug-In Hybrid Electric Vehicle Charging in the Xcel Energy Colorado Service Territory, National Renewable Energy Laboratory (NREL), 2007 (NREL/TP-640-41410).

[9] A. Brooks, Vehicle-to-grid Demonstration Project: Grid Regulation Ancillary Service with a Battery Electric Vehicle, Report Prepared by AC Propulsion for the California Air Resources Board and the California Environmental Protection Agency [Online]. Available at: http://www.udel.edu/V2G, 2002.

[10] W. Kempton, et al., A Test of Vehicle-to-grid (V2G) for Energy Storage and Frequency Regulation in the PJM System [Online]. Available at: http://www.magicconsortium.org, 2008.
[11] Vitor Duarte Fernandes Monteiro, "Desenvolvimento de um Sistema Inteligente para Carregamento de Baterias", Mestrado Integrado em Electrónica Industrial e Computadores da Universidade do Minho.

[12] L. Wang, S. Lukic, Intelligent Battery Management System for Plugin Hybrid Electric Vehicles.

[13] Borges, "M. V2G Mobile System", Final Year Project at ISEL. Documentation in Portuguese. Available at: www.deetc.isel.ipl.pt $\backslash$ matematica $j f \backslash V 2 G m o b i l e s y s t e m . p d f$

[14] Sousa, P. "Visualização de Percursos em Dispositivos Móveis", Master Project of ISEL, Available at:

www.deetc.isel.ipl.pt $\backslash m a t e m a t i c a \mid j f l p s o u s a . p d f$

Vítor Monteiro was born in Portugal, on May 1984. He finished the

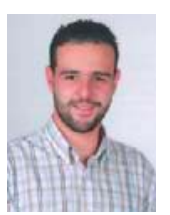
Integrated Master degree in Industrial Electronics Engineering from the University of Minho, Portugal, in 2009. Now he is a research engineer at the Department of Industrial Electronics of the University of Minho. His main researching interests are in Industrial Electronics, Electrical Vehicles and Batteries.

Dr. João Ferreira was born in Angola, June 1967. He is Professor of

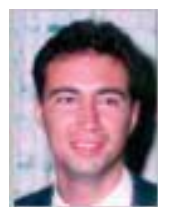
Mathematics on Informatics and Telecommunication degree courses in Polytechnic Institute of Lisbon (IPL/ISEL). He is also consultant with different companies and Portuguese institutions. He graduated in Physics at Technical University of Lisbon (UTL/IST), Portugal, received an MSC in Telecommunication and a PhD degree in Computer Science Engineering from UTL/IST. Currently, he teaches subjects in the area of mathematics and information systems and he supervises several year end, MSc and PhD students. His professional and research interests are in retrieval, geographic and multimedia retrieval, intelligent transportation (ITS) and sustainable mobility systems. As well as UML, MDE Approach, automobile business process improvements and CAD systems. He is author or co-author of more than 60 peer-reviewed scientific papers of several international conferences and workshops in different areas of computer science.

José Gabriel Pinto received the degree in Industrial Electronics Engineering and the M.Sc. degree in Industrial Electronics from the Minho University, Guimarães, Portugal, in 2001 - and 2004, respectively. From 2002 to 2006 worked as 3) invited assistant at the Electrical Department of the Polytechnic Institute of Bragança. Since 2006, works as investigator at the Energy and Power Electronics group of the Industrial Electronics Department of the Minho University. Actually he is a $\mathrm{PhD}$ scholarship in the Industrial Electronics Department of the Minho University.

Delfim Pedrosa was born in Leiria, Portugal, on July 1986. He finished the

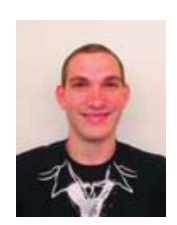
Integrated Master degree in Industrial Electronics Engineering from the University of Minho, Portugal, in 2009. Now he is a research engineer at the Department of Industrial Electronics of the University of Minho. His main researching interests are in Industrial Electronics and Electrical Vehicles.

João Luiz Afonso was born in Rio de Janeiro, Brazil, on May 05, 1963. He

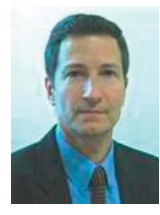
is an Associate Professor at the Department of Industrial Electronics of the University of Minho, Portugal, where he works since 1993. He received the degree in Electrical Engineering and the M.Sc. degree in Electrical Engineering from the Federal University of Rio de Janeiro, Brazil, in 1986 and 1991, respectively. In 2000, he obtained his PhD in Industrial Electronics from the University of Minho, Portugal. He lectures the subjects of Electrical Machines, Complements of Power Electronics, Electrical Power Quality, Active Power Filters, and Renewable Energy. His researching activities are related with the development of Active Power Filters, Power Quality Monitoring Systems, Power Electronics for Renewable Energy Sources and for Electric Vehicles, and with the realization of studies on Power Quality and Energy Efficiency. 